\title{
Knowledge, Attitude and Level of Competency among Pre-Intern Doctors Regarding Prevention and Cessation of Alcohol and Tobacco Consumption in Sri Lanka
}

Dissanayake DSK ${ }^{1}$, Gunawardana MDUB ${ }^{1}$, Lokuhapuarachchi LHANM ${ }^{1}$, Madushanka RDBG ${ }^{1}$, Ranasinghe ${ }^{1 *}$, Rajasuriya $\mathbf{M}^{2}$, Mahesh $\mathbf{B}^{1}$ and Padeniya PSMAB ${ }^{3}$

${ }^{1}$ Society for Health Research and Innovation (SHRI), Sri Lanka

${ }^{2}$ Department of Psychological Medicine, University of Colombo, Sri Lanka

${ }^{3}$ Lady Ridgeway Hospital for Children, Sri Lanka

*Corresponding author: Ranasinghe D, Society for Health Research and Innovation (SHRI), Sri Lanka

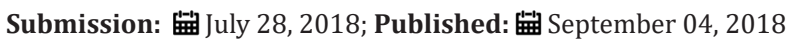

\begin{abstract}
Objective: To describe the existing knowledge among pre-intern medical graduates regarding the tobacco and alcohol prevention.

Method: A descriptive cross-sectional study was done among pre-intern medical graduates who were awaiting the medical-internship from August to November 2016. A web-based self-administered questionnaire was used. The questionnaire was developed with expert-guidance and was judgmentally-validated. The responses to selected questions were presented with the frequency and the percentage.

Results: A total of 721 pre-interns were included in the study. Of them $94.6 \%(n=682)$ were concerned on substance consumption of the patients and $96.4 \%(n=695)$ stated that it was necessary to include substance-use-history in clinical history taking. More than $95 \%(n=681)$ stated they have a role in ceasing substance-use among patients while $3.3 \%(n=24)$ thought that it was not their role. Of the participants, $82.8 \%(n=597)$ answered as being capable of identifying stages of substance-use while $15.7 \%(n=113)$ thought that they were not. Nearly $70 \%(n=506)$ answered that advising a patient once, to stop substance-use has no significant impact and $28.3 \%(\mathrm{n}=204)$ thought that it has. More than $80 \%$ thought that there is a safe-limit of alcohol consumption ( $n=595)$ while only $16 \%(n=115)$ stated that a safe limit does not exist. More than half $(52 \%, n=379)$ thought anxiety as the commonest psychiatric disorder which leads to consume alcohol. Nearly $41 \%(n=295)$ stated that nicotine-replacement therapy is available in government sector as an effective safe treatment option. Appearance of withdrawal symptoms $(96.7 \%, \mathrm{n}=697)$, continuous alcohol consumption by a cirrhotic patient $(84.9 \%, \mathrm{n}=612)$, neglecting alternative pleasures and recreational activities $(93.8 \%, \mathrm{n}=676)$, inability to control no of cigarettes smokes per day $(89.9 \%$, $\mathrm{n}=710)$ and consuming same amount of alcohol in every weekend $(12.6 \%, \mathrm{n}=91)$ were recognized as features of substance dependence by pre-interns.

Conclusion: There are inadequacies of the knowledge on selected aspects of tobacco and alcohol prevention among pre-intern medical graduates. A comprehensive, well-planned orientation using effective teaching methods on these aspects prior to the commencement of medical internship would be beneficial for the patient management.
\end{abstract}

Keywords: Tobacco and alcohol cessation; Competency building

\section{Introduction}

\section{Background}

Consumption of tobacco and alcohol is a major risk factor contributing to the global burden of disease [1]. Harmful use of alcohol is considered to be among the top five factors leading to disease, disability and death worldwide [2]. It contributes much towards the non-communicable diseases (NCD), which has already become a rising global epidemic. Both tobacco and alcohol are found to be the major modifiable risk factors for cardiovascular diseases, cerebrovascular accidents [3,4], metabolic syndrome [5,6], psychological disorders [4-7] and a plethora of malignancies
[3-10]. These psychoactive substances play a major burden to the health care delivery system in Sri Lanka [11]. Alcohol and tobacco are amongst the most abusing substances throughout the world. More over these substances are used together with a significant correlation [12]. Hence dependence on both substances can coexist. According to a survey conducted by the World Health Organization, global tobacco use has been reported as over 1.1 billion in 2014 [13] and it has been $9.3 \%$ among the Sri Lankan population in 2012 [14]. Worldwide per capita consumption of alcohol among the population aged over 15 years in 2010 was 6.2 liters [2]. The national per capita consumption of alcohol has shown a consistent 
increase over the last few decades, from 2.2 liters in 2003, 3.7 liters in 2010 [15] and 4.9 liters in 2014 [2] and the prevalence of drinking among females is increasing. Out of the Sri Lankan population $29.7 \%$ are either abuse or dependent on alcohol. But there is definite underreporting due to high consumption of illicit alcohol in Sri Lanka [16].

Elimination of exposure to tobacco and alcohol has shown a significant reduction NCDs. A recent systematic review concluded that the cessation of tobacco smoking has significantly reduced the progression of atherosclerotic disease and improved the respiratory function among those who were affected with chronic respiratory diseases [17]. A meta-analysis of prospective studies conducted in 2012 concluded that the risk of metabolic syndrome is reduced with the cessation of smoking [5]. A French study found that the cessation of smoking is associated with the risk reduction of head and neck cancers reaching the level of non-smokers in 20 years [18]. There is high quality evidence suggesting that the doctors have a pivotal role in the reduction of alcohol and tobacco consumption among patients. Brief physician advice for problem drinkers has been associated with sustained reduction of alcohol consumption in randomized controlled clinical trials [19-21]. Similarly, simple interviews by doctors have shown an effective reduction and long-term abstinence from smoking among the patients [22,23]. Effectiveness of such interventions may invariably depend on the doctors' knowledge, perceptions towards smoking and alcohol prevention and their competency in conducting such interviews. A few international studies have found that the knowledge, skills and attitude towards alcohol and smoking among medical students and doctors are inadequate [24-27]. As well there are no well-defined guidelines to manage risk factors of NCDs locally and globally. Intern doctors are the first contacts of most of the patients. Hence improving skills and competency in directing patients towards quitting of alcohol and tobacco among pre-intern doctors is crucial. To the best of our knowledge, no studies have assessed the level of competency of pre-intern doctors regarding smoking and alcohol prevention. Thus, we intended to assess the knowledge, perceptions and skills towards cessation of smoking and alcohol among a nationally representative cohort of Sri Lankan pre-intern doctors.

\section{Methodology}

This study was conducted with the collaboration of World Health Organization, National Authority on Tobacco and Alcohol (NATA), Society for Health Research and Innovation (SHRI) and Government Medical Officers' Association. It was a descriptive cross-sectional study which was conducted during Good Intern Program 4 in 2016; a programmed which included most of the graduated pre-intern doctors representing almost all universities as well the foreign graduates who were eligible for the internship in Sri Lanka. Pre-inter doctors who got registered during the period of October 2016 to November 2016 were included.

The participants were provided a self-administered questionnaire (Annexure 3) in electronic format which was to be filled during the registration process for the programmed and only for those who were consented for the study. It had three components to assess the perception, knowledge and level of competency in advising and helping patients to quit alcohol or cease tobacco use. It had both positive and negative questions to improve the validity of the questionnaire. In the absence of previous studies in a similar population, we assumed that the prevalence of high knowledge and perception regarding smoking and alcohol prevention is $50 \%$ and calculated the sample size based on the formula given below Figure 1 .

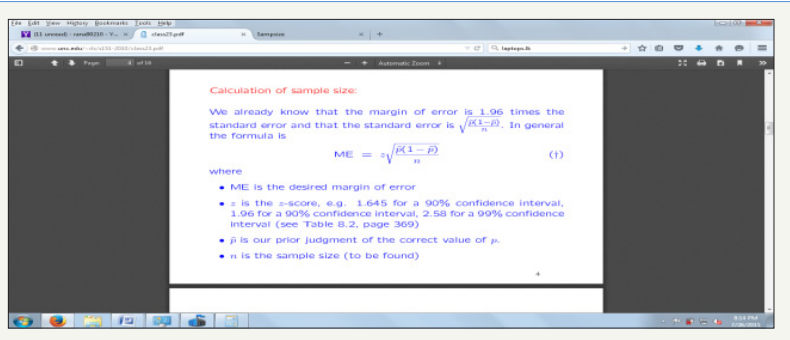

Figure 1: Calculation of sample size.

ME: Margin of Error (5\%); Z: Z score (1.96 for 95\% confidence interval); $p$ : Prior judgment of proportion $(50 \%)$; $\mathrm{N}$ : Sample size

Based on the above calculation the required sample size was 385 . We assumed a non-response rate of $15 \%$ and hence the final sample required was calculated as 450 . Collected data was analyzed and presented using the standard descriptive statistics. This study confirmed the provisions of Declaration of Helsinki. Participants were provided the electronic information sheet and the informed consent form. Furthermore, the subjects were given detailed information about the nature of the research, what was expected from them prior to the study. These forms were in English since the undergraduate curriculum of Sri Lankan medical students is conducted only in English. The contact numbers of the principal investigators were displayed at electronic information sheet for all the participants for necessary clarifications. This research had no any potential risk for the participants. Withholding participation from this study did not affect the pre-intern doctors on the course of GIP. They had no obligations to participate in the study for the successful completion of the programmed. Participants were provided relevant updated electronic material regarding tobacco and alcohol prevention and cessation free of charge during the GIP. The participants had reserved the right to withhold or withdraw consent at any time. No personal details were collected. The electronic data sheets were stored in a password protected computer.

Only the principal investigator had the access to the data sheets. Thus, confidentiality was maintained throughout the study. Ethical clearance was obtained from the Ethics Review Committee of the Faculty of Medicine University of Colombo. The authors declared that they did not have potential conflicts of interests.

At the end of the good intern programmed under the symposium "Motivating the patient for healthy life style" all the participants were given Virtual Learning Environment (VLE) with clinical cases was developed to fill the gaps identified in knowledge 
and to enhance skills of the pre-interns with the guidance from specialists in the management of a patient towards quitting alcohol and cigarettes.

\section{Results}

Among the GIP participants 721 had participated in the study. Majority of them ( $n=157,21 \%)$ were from faculty of Medicine Colombo, while the foreign graduates and from the graduates of Faculty of Medical Science in Sri Jayewardenepura represented the next higher responsive rates. In section one which assed the level of perception, number of 682 participants (94.6\%) among total has agreed to concern regarding substance use in patients while $28(3.6 \%)$ of them disagreed. 695 (94.6\%) of subjects accepted the necessity of a substance use history in clinical history taking. Only 15 (2.1\%) disagreed regarding including of the substance use history. As doctors 686(95.1\%) of participated pre-interns have thought that they are having a role in cessation of substance use among patients; but 24(3.3\%) among them had a contrast idea. $597(82.7 \%)$ of participants were capable of identifying the stage of substance use whereas $113(15.7 \%)$ were incapable to identify the stage. Referring the substance use patients for specialized centers when needed was an accepted method of 693(96.1\%) of preinterns I their management plan of a patient with substance use. But $17(2.4 \%)$ did not accept that. Knowledge regarding management of a patient with substance use was assessed in the second section of the questionnaire where advising a patient to stop substance use by doctors for five minutes were thought to have no impact by $506(70.2 \%)$ participants. 204(28.3\%) of pre-interns had accepted it. $595(82.5 \%)$ of participants had thought that there is a safe limit for alcohol while $115(16 \%)$ denied it.

415(57.6\%) answered as nicotine replacement therapy is safe and available in government sector. But 295(40.9\%) stated it is not. Anxiety was thought to be the commonest psychiatry disorder which has lead the patient to use substance by $379(52.9 \%)$ of participants. In contrast 331(45.9\%) had mentioned that it is not the anxiety. Question asked regarding the dependency of substance use was answered as below Table 1 .

Table 1: Dependency of substance use.

\begin{tabular}{|l|l|l|l|l|}
\hline Question & \multicolumn{2}{|c|}{ Yes } & \multicolumn{2}{c|}{ No } \\
\hline & Number & Percentage & Number & Percentage \\
\hline
\end{tabular}

In section three of the questionnaire level of competency was assessed. There were two case scenarios regarding patients who were on alcohol and cigarette respectively. 470(65.2\%) among participants had stated that they have the competency to advise the patient directly, to stop alcohol use while 187(25.8\%) of them were unsure whether patient will accept the house officer's advice. Referring the patient to a psychiatry unit and to specialized centers were found to be an accepted method by 481(66.7\%) and $588(81.6 \%)$ of participants respectively. Meanwhile 229(31.8\%) had not accept the referral to a psychiatry unit and $29(4 \%)$ for specialized centers.279(38.9\%) pre-interns had chosen to ask senior help to advise the patient, thinking that patient won't follow their advice whistle 259(35.7\%) of them disagreed that. Advising the patient in follow up visit also accepted by 591(82\%) though the participants stated as they were competent to advise the patient at first contact. Second case scenario which was regarding a cigarette smoking patient who had a myocardial infarction had similar questions to case scenario one. Similar response rates were there as below. Advising at first contact Asking senior help Referring Providing advice next visit

\section{Discussion}

Tobacco and alcohol have been identified as risk factors for most of the NCDs. It's been revealing that these substance and alcohol use are been increasing among population. So, it has become a global epidemic. Prompt action has to be taken as the population is drowning in NCDs. Globally as regionally and locally guidelines have been developed to manage major NCDs. But no guideline has been developed yet to address and control risk factors. This study was conducted with the intention of standardizing the level if competency among doctors to prevent or cease the use of tobacco and alcohol. Pre-intern doctors were targeted as they are new to the health system of the country and have been the first contact doctor at most occasions. Good intern programme was an ideal place in which most of the deficiencies of medical graduates were fulfilled and converted them to good intern house officers. There is a well know deficiency in substance use history in routine history taking from a patient. Most of the participants agreed to concern about substance history and about $96 \%$ stated that it is necessary to include substance use component in history taking even though it has been missed during most of the histories in a usual hospital setting. Around $95 \%$ of the participants thought that there is a role for as doctors to prevent alcohol use and tobacco cessation, without knowing the exact method. No proper guidelines have been published regarding the current burning issue of tobacco and alcohol use. Hence majority (around 96\%) of them had chosen the answer to referring the patient to specialized centers Among the participants nearly $70 \%$ stated that there was no effect of advising patients regarding tobacco cessation and alcohol prevention at once. But brief advice by physician for problem drinkers has been shown sustained reduction of alcohol consumption in clinical trials [19-21]. Similarly, simple interviews by doctors have shown an effective reduction and long-term abstinence from smoking among the patients $[22,23]$. Some answers of the second component the questionnaire was unsatisfactory. As an example, around $80 \%$ accepted that there is a safe limit for alcohol. More than $50 \%$ of the subjects though those government hospitals have nicotine replacement chewing gum. Unfortunately, only at NHSL Psychiatry unit have those not in other government hospitals. Alcohol dependency features seemed to be well-known from them. Most of the participant had selected the correct answers.

Level of competency seemed to be low even though participant stated that they were confident enough to advise patient to stop alcohol and smoking. Majority preferred referring the patients to specialized centers or psychiatry units. This area level of 
competency is unsatisfactory. Most of patient won't go for psychiatrist or specialized centers though they were properly referred due to the stigma and no desire to stop those. Hence some people will lose the management midway. It will be more effective if doctors are confident to advise at first contact and stepping up the patient from pre-contemplation to contemplation or action stage in cycle of change and to follow up at same setting.

\section{Conclusion and Recommendations}

According to the current study there are inadequacies of the knowledge on selected aspects of tobacco and alcohol prevention among pre-intern medical graduates. A comprehensive, wellplanned orientation using effective teaching methods on these aspects prior to the commencement of medical internship would be beneficial for the patient management. Establishing a well analyzed specific guidelines for risk factors management ought to be thought when considering the NCD burden to the country and to the world. Experts who are working along this aspect have highlighted the necessity of having a comprehensive management strategy of the users of these risk factors. There quick assessment of patients who need intervention has to be developed and there onwards management can be formulated. As there is a well-known deficiency in including substance history, risk patient identification is very often missed. Hence along with this study in collaboration with WHO, NATA, Health Ministry and GMOA as SHRI we designed a screening tool for the quick assessment of alcohol and tobacco use among patients irrespective of their presenting complaint. This approach in other way helps for holistic management of the patient at any setting. A series of discussion with expertise in the field of tobacco and alcohol prevention were conducted regarding the stamp and formulating an allorhythmia with management strategies which can be carried out as the first contact doctor. A rubber stamp to assess substance use history was developed to use at wards and OPDs for each patient. This in-turn standardize the substance use history taking among doctors. Pilot studies can be carried out at selected hospital settings to assess feasibility of the project. According to the feedback and pilot project assessment this can be implemented as a project through a circular which will be issued by the Ministry of Health

\section{TAP-Q seal}

This seal can be put on every BHT and clinic book and HO or first contact doctor has to fill it. The management algorithm as below. Patients with marked TAP-Q seal with
A. Daily substance use
B. Binge alcohol use
C. Impact on patient either by directly or indirectly due to substances

need further follow ups.

Management during follow up visits as below.

If there are no serious
A. Physical health or

B. Mental health deterioration

Same first contact doctor can

A. Educate the patient regarding; Prevailing consequences Possible consequences that would arise the immediate and long-term benefits from cessation Obstacles that might be encountered by the cessation

B. Empower the patient; Provide an individualized action plan Setup goals ("SMART"-specific, measurable, achievable, realistic, time bound)

Then review the patient with at least two follow up visits with TAP Q Seal

$1^{\text {st }}$ review-after one month

$2^{\text {nd }}$ review- 2 months from the first visit (First review should be done at least within one month.

In the TAP Q Seal if following are present;

A. Daily consumption of Alcohol/Tobacco.

B. Binge drinking of Alcohol.

C. An impact on patient/patient's family due to substance consumption of patient/family member.

D. Presence of serious physical or mental health deterioration.

E. If no improvement following 2 follow up visits.

Refer those patients to specialists. Later on, Ministry of health can have projects to develop designated MOs who are specialized in alcohol, tobacco and substance use quitting methods and strategies. This level can be used to minimize unnecessary referral for psychiatry units. This can be used as a sustainable and costeffective project, making doctors accountable for prevention of tobacco and alcohol in a standardized manner.

\section{Acknowledgement}

Concept: Dr. Anuruddha Padeniya Consultant Paediatric Neurologist Founder-Good Intern Programme. Resource Personnel: Dr Palitha Abeykoon: Chairman- National Authority on Tobacco and Alcohol (NATA) Adviser-World Health Organization, Prof. Diyanath Samarasinghe: Professor in Psychiatry Faculty of Medicine, University of Colombo. Dr. Mahesh Rajasuriya: Consultant Psychiatrist, Senior Lecturer, Faculty of Medicine, University of Colombo.

\section{References}

1. Ezzati M, Lopez AD, Rodgers A, Murray CJ (2004) Comparative quantification of health risks. Global and regional burden of disease attributable to selected major risk factors Geneva: World Health Organization: 1987-1997.

2. WHO (2014) Global status report on alcohol and health: World Health Organization. 
3. Rehm J, Taylor B, Room R (2006) Global burden of disease from alcohol illicit drugs and tobacco. Drug and alcohol review 25(6): 503-513.

4. Murray CJ, Lopez AD (1997) Global mortality, disability, and the contribution of risk factors: Global burden of disease study. The Lancet 349(9063): 1436-1442.

5. Sun K, Liu J, Ning G (2012) Active smoking and risk of metabolic syndrome: a meta-analysis of prospective studies. PLoS One $7(10)$ : e47791.

6. Djoussé L, Arnett DK, Eckfeldt JH, Province MA, Singer MR, et al. (2004) Alcohol consumption and metabolic syndrome: does the type of beverage matter? Obesity Research 12(9): 1375-1385.

7. Jane-Llopis E, Jané-Llopis E, Matytsina I, Jané-Llopis E, Matytsina I (2006) Mental health and alcohol, drugs and tobacco: a review of the comorbidity between mental disorders and the use of alcohol, tobacco and illicit drugs. Drug and alcohol review 25(6): 515-536.

8. Vineis P, Alavanja M, Buffler P, Fontham E, Franceschi S, et al. (2004) Tobacco and cancer: recent epidemiological evidence. Journal of the National Cancer Institute 96(2): 99-106.

9. Iodice S, Gandini S, Maisonneuve P, Lowenfels AB (2008) Tobacco and the risk of pancreatic cancer: a review and meta-analysis. Langenbeck's Archives of Surgery 393(4): 535-545.

10. Jha $P$ (2009) Avoidable global cancer deaths and total deaths from smoking. Nature Reviews Cancer 9(9): 655-664.

11. Assunta M (2001) Impact of alcohol consumption on Asia. The Globe $3(4)$.

12. Katulanda P, Ranasinghe C, Rathnapala A, Karunaratne N, Sheriff R, et al. (2014) Prevalence, patterns and correlates of alcohol consumption and its' association with tobacco smoking among Sri Lankan adults: a crosssectional study. BMC public health 14(1): 1 .

13. WHO (2015) Global Health Observatory (GHO) data prevalence of tobacco smoking.

14. Athauda L, Wickremasinghe A (2015) Trend of smoking and tobacco use in Sri Lanka 1960-2010: Is it affected by cigarette pricing?

15. Somatunga L, Ratnayake L, Wijesinghe W, Yapa Y, Cooray M (2014) National alcohol use prevalence survey in Sri Lanka. Journal of the Postgraduate Institute of Medicine Vol. 1.
16. De Silva V, Samarasinghe D, Gunawardena N (2009) Alcohol and tobacco use among males in two districts in Sri Lanka. Ceylon Medical Journal 54(4): 119-124

17. Glantz S, Gonzalez M (2012) Effective tobacco control is key to rapid progress in reduction of non-communicable diseases. Lancet 379(9822): 1269-1271.

18. Marron M, Boffetta P, Zhang Z-F, Zaridze D, Wünsch-Filho V, et al. (2010) Cessation of alcohol drinking, tobacco smoking and the reversal of head and neck cancer risk. International Journal of Epidemiology 39(1): 182196.

19. Fleming MF, Barry KL, Manwell LB, Johnson K, London R (1997) Brief physician advice for problem alcohol drinkers: a randomized controlled trial in community-based primary care practices. JAMA 277(13): 10391045 .

20. Fleming MF, Mundt MP, French MT, Manwell LB, Stauffacher EA, et al. (2002) Brief physician advice for problem drinkers: long-term efficacy and benefit-cost analysis. Alcoholism: Clinical and Experimental Research 26(1): 36-43.

21. Fleming MF, Mundt MP, French MT, Manwell LB, Stauffacher EA (2000) Benefit-cost analysis of brief physician advice with problem drinkers in primary care settings. Medical Care 38(1): 7-18.

22. Cummings SR, Coates TJ, Richard RJ, Hansen B, Zahnd EG, et al. (1989) Training physicians in counseling about smoking cessation: a randomized trial of the Quit for Life program. Annals of Internal Medicine 110(8): 640-647.

23. Cummings SR, Rubin SM, Oster G (1989) The cost-effectiveness of counseling smokers to quit. JAMA 261(1): 75-79.

24. Cape G, Hannah A, Sellman D (2006) A longitudinal evaluation of medical student knowledge, skills and attitudes to alcohol and drugs. Addiction 101(6): 841-849.

25. Kelleher S (2007) Health care professionals' knowledge and attitudes regarding substance use and substance users. Accident and emergency nursing 15(3): 161-165.

26. Kelleher S, Cotter PA (2009) Descriptive study on emergency department doctors' and nurses' knowledge and attitudes concerning substance use and substance users. International Emergency Nursing 17(1): 3-14.

27. Thankappan K, Pradeepkumar A, Nichter M (2009) Doctors' behaviour \& skills for tobacco cessation in Kerala.
Creative Commons Attribution 4.0

International License

For possible submissions Click Here
Submit Article

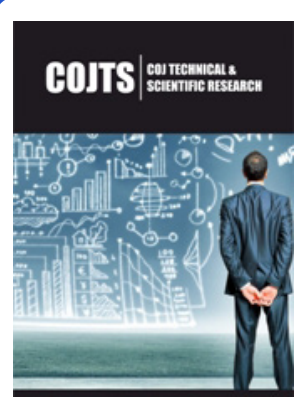

\section{COJ Technical \& Scientific Research}

\section{Benefits of Publishing with us}

- High-level peer review and editorial services

- Freely accessible online immediately upon publication

- Authors retain the copyright to their work

- Licensing it under a Creative Commons license

- Visibility through different online platforms 